\title{
SYNTHESIS, CHARACTERIZATION, AND ANTHELMINTIC ACTIVITY OF NOVEL BENZOTHIAZOLE DERIVATIVES CONTAINING INDOLE MOIETIES
}

\author{
ALETI RAJAREDDY ${ }^{1 *}$, SRINIVAS MURTHY M $^{2}$ \\ ${ }^{1}$ Department of Pharmaceutical Chemistry, Mall Reddy Pharmacy College, Secunderabad, Telangana, India, ${ }^{2}$ Department of \\ Pharmaceutical Chemistry, Vignan Institute of Pharmaceutical Sciences, Deshmukhi, Telangana, India. \\ Email: rajareddyaleti050@gmail.com
}

Received: 31 October 2018, Revised and Accepted: 06 January 2019

ABSTRACT

Objective: The objective of this study was to synthesize and evaluate the anthelmintic activity (AA) of novel benzothiazole derivatives containing indole moieties (BDIM).

Methods: The present works which involve the substituted isatin Schiff bases undergo acetylating and reacting with 2-aminobenzothiazole to give novel BDIM.

Results: All the newly synthesized molecules (5a-5o) were characterized by Fourier-transform infrared spectroscopy, H-nuclear magnetic resonance, and mass spectral analysis along with physical data. The biological potentials of the newly synthesized compounds are evaluated for their AA using an Indian earthworm (Pheretima posthuma), and albendazole was used as standard drug.

Conclusion: The synthesized compound 5f, 5n, and 5o showed good AA, whereas others exhibited significant activities.

Keywords: Substituted benzaldehyde, Isatin, p-Toluidine, 2-aminobenzothiazole, Anthelmintic activity.

(C) 2019 The Authors. Published by Innovare Academic Sciences Pvt Ltd. This is an open access article under the CC BY license (http://creativecommons. org/licenses/by/4. 0/) DOI: http://dx.doi.org/10.22159/ajpcr.2019.v12i3.30530

\section{INTRODUCTION}

Heterocyclic compounds are those which have a cyclic structure with two, or more, different kinds of atom in the ring. This two kinds of atoms are like carbon and the other elements (heteroatoms), most often $\mathrm{N}, \mathrm{O}$ and $\mathrm{S}$. Although the parent compound, benzothiazole is not widely used, many of its derivatives are found in commercial products or in nature[1-3]. Benzothiazole ring found to be possessing pharmacological activities such as antitumor, antitubercular, antimalarial, anticonvulsant, anthelmintic, analgesic, anti inflammatory and antifungal. Isatin or $1 \mathrm{H}$-indole-2, 3-dione is an indole derivative. Indole derivatives have acquired conspicuous significance due to their wide spectrum of biological activities.

In view of the high degree of bioactivity shown by the benzothiazole derivatives mentioned above facts, we aimed to construct a system combining both these vital moieties such as benzothiazole and indole in a single molecular framework, together with an exploration of the additive effects of their biological activities. Hence, we describe here in the synthesis, characterization, and anthelmintic activity (AA) of novel benzothiazole derivatives containing indole moieties (BDIM).

\section{METHODS}

The synthesized compounds were screened for anthelmintic activities [4-7]. The IR spectra were recorded on a Shimadzu 8700 spectrometer using the ATR technique (Attenuated Total Reflectance) in the range of 400-4000 $\mathrm{cm}-1$. and values are reported in $\mathrm{cm}^{-1}$ and the spectra were interpreted. ${ }^{1} \mathrm{H}$-nuclear magnetic resonance (NMR) spectra were recorded on DPX-200 MHz NMR spectrometer using dimethyl sulfoxide (DMSO)- $\mathrm{d}_{6}$ and chemical shifts $(\delta)$ are reported in parts per million downfield from internal reference tetramethylsilane , and the spectra were interpreted. Mass spectra were recorded on mass spectrophotometer (model Shimadzu) by Liquid chromatography-mass spectrometry (LC-MS) and the spectra were interpreted. Precoated
Silica gel G plates were used to monitor the progress of reaction as well as to check the purity of the compounds: n-Hexane:ethyl acetate (8:2).

General procedures for the preparation of 2-aminobenzothiazole (2-ABT)

Aniline ( $4.6 \mathrm{~g}, 0.05 \mathrm{~mol})$ and potassium thiocyanate $(3.8 \mathrm{~g}, 0.05 \mathrm{~mol})$ were dissolved in absolute ethanol containing $4 \mathrm{ml}$ of concentrated hydrochloric acid $(\mathrm{HCl})$. To this mixture, bromine in glacial acetic acid $(6.75 \mathrm{ml}, 0.125 \mathrm{~mol})$ was added and the reaction mixture was refluxed for $1 \mathrm{~h}$. Then, it was cooled in ice bath. The precipitate obtained was filtered, washed with cold water, and dried. The crude product was recrystallized from ethanol [8].

\section{Synthesis of substituted isatin from aniline}

In a round-bottomed flask are placed 9gm of chloral hydrate and $120 \mathrm{ml}$ of water. To this solution are then added, in order: $13 \mathrm{gm}$ of crystallized sodium sulphate, a solution of $4.5 \mathrm{gm}$ of aniline in $30 \mathrm{ml}$ of water to which $5.12 \mathrm{gm}$ of concentrated hydrochloric acid has been added to dissolve the amine and finally, a solution of $11 \mathrm{gm}$ of 5 hydrochlorid in $50 \mathrm{ml}$ of water. Flask was then heated vigorously until the reaction was completed. After it, the solution containing beaker was cooled in running water followed by the filtration of reminder crystallized product with suction pump and air dried. $18.4 \mathrm{~g}$ of concentrated sulfuric acid $(10.0 \mathrm{ml})$ was warmed to $50^{\circ} \mathrm{C}$ and $2.5 \mathrm{~g}$ of dry isonitrosoacetanilide was added in such a rate so as to keep the temperature between $60^{\circ} \mathrm{C}$ and $70^{\circ} \mathrm{C}$ but not higher. External cooling was applied at this stage so that the reaction could be carried out more rapidly after the addition of isonitroso compound was finished. The solution was heated to $80^{\circ} \mathrm{C}$ and kept at this temperature for about 10 min to complete the reaction. Then, the reaction mixture was cooled to room temperature and poured it into 10 times its volume of cracked ice. After standing for $90 \mathrm{~min}$, the final product was filtered with suction pump followed by washing with cold water to remove sulfuric acid and dried in air. 
Synthesis of isatin schiff bases (ISB) (3a-3i)

A mixture of equimolar quantity of substituted aromatic aniline $(0.01 \mathrm{~mol})$ and compound $2 \mathrm{a}-2 \mathrm{~d}$ was dissolved in $20 \mathrm{ml}$ of ethanol and refluxed for $2-3 \mathrm{~h}$ in the presence of few drops of $2 \mathrm{ml}$ glacial acetic acid. The progress of the reaction was monitored by thin-layer chromatography (TLC) (n-Hexane:EtoAc 7:3). The reaction mixture was cooled to room temperature and kept in the refrigerator for overnight to get precipitate. A solid was obtained, which was filtered off and recrystallized from methanol or ethanol to give crystalline solid.[9]

Synthesis of 1-acetyl-3-(phenylimino) indolin-2-one derivatives A mixture of equimolar (0.01) quantity of compound (3a-3i, ISB) and $5.1 \mathrm{ml}$ of acetic anhydride was taken in to $250 \mathrm{ml}$ round bottom flask. Then, whole of the content was of refluxed for about $4 \mathrm{~h}$, and then, the solution was poured into beaker containing crushed ice followed by the filtration and drying of the product.

General procedure for the synthesis of novel 1-((E)-1-(benzo[d] thiazol-2-yl) imino) ethyl)-3-(phenylimino) indolin-2-one (5a-5o) A mixture of equimolar quantity of substituted $\mathrm{N}$-acetyl isatin derivatives $(0.01 \mathrm{~mol})$ and compound $1 \mathrm{a}-1 \mathrm{~b}$ was dissolved in $20 \mathrm{ml}$ of ethanol and refluxed for $2-3 \mathrm{~h}$ in the presence of few drops of $2 \mathrm{ml}$ glacial acetic acid. The progress of the reaction was monitored by TLC (n-Hexane:EtoAc $8: 2$ ). The reaction mixture was cooled to room temperature and kept in the refrigerator for overnight to get precipitate. A solid was obtained, which was filtered off and recrystallized from methanol or ethanol to give crystalline solid (Fig. 1)

5a: (E)-1-((E)-1-(benzo[d]thiazol-2-yl) imino) ethyl)-3(phenylimino) indolin-2-one

M.P. $219-221^{\circ} \mathrm{C}$; Mol. formula: $\mathrm{C}_{23} \mathrm{H}_{16} \mathrm{~N}_{4} \mathrm{OS}$, yield $78 \%$, IR $\left(v \mathrm{~cm}^{-1}\right)$ : 3143, 3054 (C-H Str, Ar), 2930, 2891, 2793 (C-H Str, Aliphatic), 2311 (C-S-C Str), 1684 (C=O Str, Indole), 1588 (C=N Str), 1515 (C=CH Str), 1431 (C=C Str, Ar). ${ }^{1} \mathrm{H}-\mathrm{NMR}$ (DMSO) $\delta \delta$ ppm: 8.38-8.27 (d, 2H, Ar-H), 8.11-7.88 (d, 2H, Ar-H), 7.84-7.77(t, 3H, Ar-H), 7.69-7.67 (d, 2H, Ar-H), 7.55-7.54 (d, 2H, Ar-H), 7.51-7.41 (t, 3H, Ar-H). 3.33 (S, 3H, - $\mathrm{CH}_{3}$ ); Mass (ESI-MS): m/z 396 (M), 397 (M+1, 100\%).

5b: (E)-5-chloro-1-((E)-1-(benzo[d]thiazol-2-yl) imino) ethyl)-3(phenylimino) indolin-2-on

M.P. $213-215^{\circ} \mathrm{C}$; Mol. formula: $\mathrm{C}_{23} \mathrm{H}_{15} \mathrm{~N}_{4}$ OSCl, yield $82 \%$,IR $\left(v \mathrm{~cm}^{-1}\right)$ : 3037, 2932 (C-H Str, Ar), 2872 (C-H Str, Aliphatic), 2346 (C-S-C Str), 1721 (C=0 Str, Indole), 1555 (C=N Str), 1520 (C=CH Str), 1432 (C=C Str, Ar), 771 (C-Cl Str, Ar). ${ }^{1} \mathrm{H}-\mathrm{NMR}$ (DMSO) $\delta \delta$ ppm: 8.37-8.28 (t, 3H, ArH), 7.88-7.84 (t, 3H, Ar-H), $8.10(\mathrm{~s}, 1 \mathrm{H}, \mathrm{Ar}-\mathrm{H}), 7.83-7.68(\mathrm{~d}, 4 \mathrm{H}, \mathrm{Ar}-\mathrm{H})$, 7.58-7.57 (d, 2H, Ar-H), 7.55-7.51 (d, 2H, Ar-H), 3.39 (s, 3H, - $\mathrm{CH}_{3}$ ); Mass (ESI-MS): m/z 430 (M), 431 (M+1, 100\%),432 (M+2, 30\%)

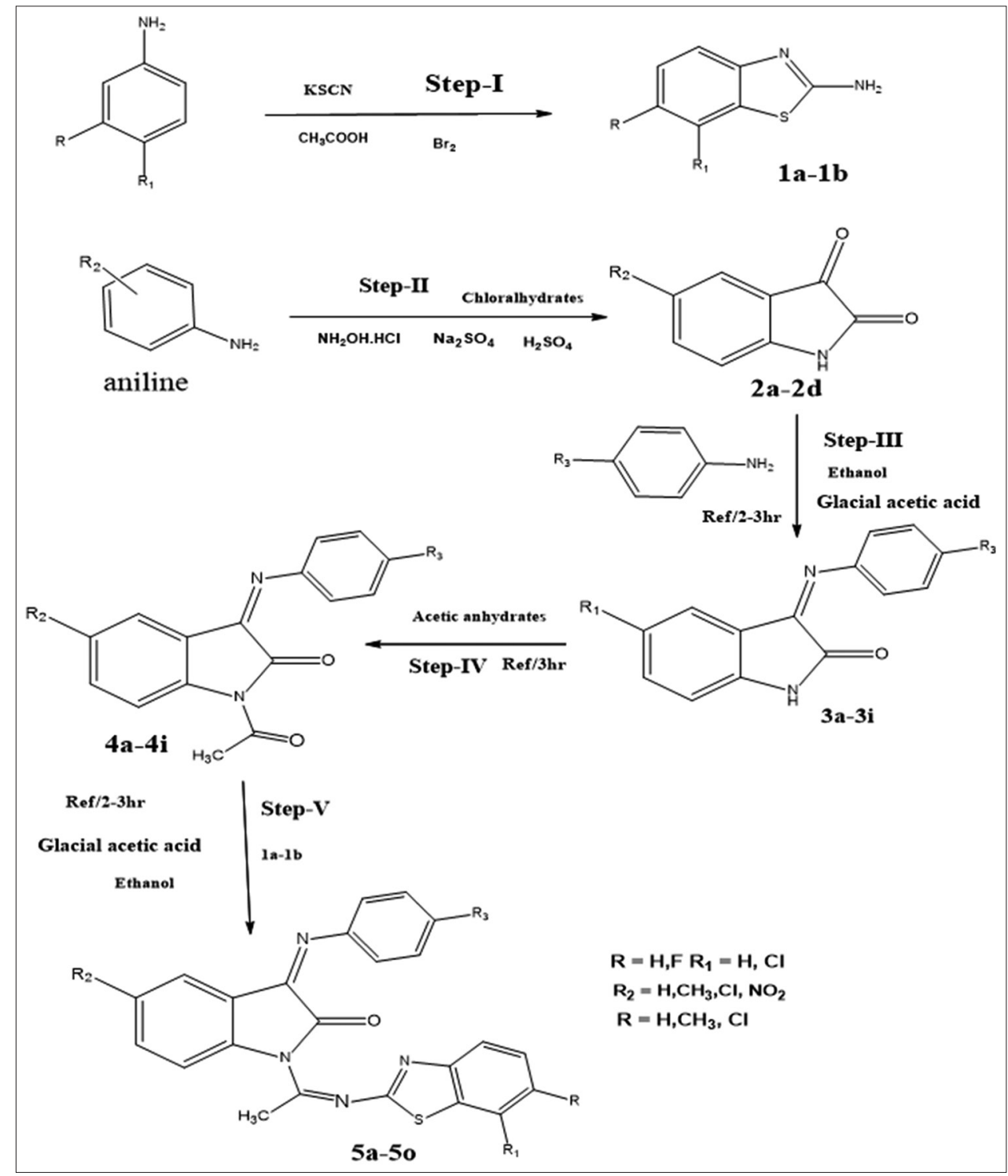

Fig. 1: Synthetic scheme 
5c: (E)-1-((E)-1-(benzo[d]thiazol-2-yl) imino) ethyl)-3-(ptolylimino) indolin-2-one

M.P. 203-205 ${ }^{\circ}$; Mol. formula: $\mathrm{C}_{24} \mathrm{H}_{18} \mathrm{~N}_{4} \mathrm{OS}$, yield $77 \%$. IR $\left(v \mathrm{~cm}^{-1}\right)$ : IR $\left(v \mathrm{~cm}^{-1}\right): 3100$ (C-H Str, Ar), 2987, 2882 (C-H Str, Aliphatic), 2336 (C-S-C Str), 1705 (C=0 Str, Indole), 1663, 1546 (C=N Str), 1506 (C=CH Str), 1459 (C=C Str, Ar), 797 (C-Cl Str, Ar), 588 (C-F Str, Ar). ${ }^{1}$ H-NMR (DMSO) $\delta \delta$ ppm: 8.57-8.35 (d, 4H, Ar-H), 8.06-8.04 (d, 4H, Ar-H), 7.94$7.92(\mathrm{t}, 2 \mathrm{H}, \mathrm{Ar}-\mathrm{H}), 7.82-7.75(\mathrm{t}, 2 \mathrm{H}, \mathrm{Ar}-\mathrm{H}), 3.31\left(\mathrm{~s}, 3 \mathrm{H},-\mathrm{CH}_{3}\right), 1.97-1.94$ (s, $3 \mathrm{H},-\mathrm{CH}_{3}$ ); Mass (ESI-MS): m/z 410 (M), 411 (M+1, 100\%).

5d: (E)-5-chloro-1-((E)-1-(benzo[d]thiazol-2-yl) imino)ethyl)-3(p-tolylimino)indolin-2-one

M.P. $231-233^{\circ} \mathrm{C}$; Mol. formula: $\mathrm{C}_{24} \mathrm{H}_{17} \mathrm{~N}_{4} \mathrm{OSCl}$, yield $66 \%$. IR $\left(v \mathrm{~cm}^{-1}\right)$ : 3093 (C-H Str, Ar), 2976, 2884 (C-H Str, Aliphatic), 2383 (C-S-C Str), 1699 (C=0 Str, Indole), 1578 (C=N Str), 1565 (C=CH Str), 1476 (C=C Str, Ar), 803 (C-Cl Str, Ar). ${ }^{1} \mathrm{H}-\mathrm{NMR}$ (DMSO) $\delta \delta$ ppm: 8.47-8.37 (d, 2H, Ar-H), 7.95-7.88 (d, 4H, Ar-H), 7.40-7.39 (t, 2H, Ar-H), $7.35\left(\mathrm{~s},{ }^{1} \mathrm{H}\right.$, Ar-H), 7.35-7.34 (d, 2H, Ar-H), 3.34-3.30 (s, 3H, $-\mathrm{CH}_{3}$ ), 1.986-1.982 (s, 3H, - $\mathrm{CH}_{3}$ ); Mass (ESI-MS): m/z 444 (M), 445 (M+1, 100\%), 446 $(\mathrm{M}+2,30 \%)$.

5e: (E)-1-((E)-1-((benzo[d]thiazol-2-yl) imino) ethyl)-3(phenylimino) indolin-2-one

M.P. $191-193^{\circ} \mathrm{C}$; Mol. formula: $\mathrm{C}_{24} \mathrm{H}_{18} \mathrm{~N}_{4} \mathrm{OS}$, yield $67 \%$. IR $\left(v \mathrm{~cm}^{-1}\right)$ : 3065(C-H Str, Ar), 2987, 2894 (C-H Str, Aliphatic), 2365 (C-S-C Str), $1716 \mathrm{C}=0$ Str, Indole), 1584 (C=N Str), 1543 (C=CH Str), 1467 (C=C Str, Ar), ${ }^{1} \mathrm{H}-\mathrm{NMR}$ (DMSO) $\delta \delta$ ppm: 7.98-7.90 (d, $2 \mathrm{H}, \mathrm{Ar}-\mathrm{H}$ ), 7.78-7.80 (d, $2 \mathrm{H}$, $\mathrm{Ar}-\mathrm{H}), 7.68-7.67$ (d, 2H, Ar-H), 7.40-7.39 (t, 2H, Ar-H), 7.29-7.28 (t, 3H, $\mathrm{Ar}-\mathrm{H}), 7.14-7.10(\mathrm{t}, 2 \mathrm{H}, \mathrm{Ar}-\mathrm{H}), 2.14-2.10\left(\mathrm{~s}, 3 \mathrm{H},-\mathrm{CH}_{3}\right.$ ); Mass (ESI-MS): $\mathrm{m} / \mathrm{z} 410(\mathrm{M}), 411(\mathrm{M}+1,100 \%)$. 5f: (E)-5-methyl-1-((E)-1-((benzo[d]thiazol-2-yl) imino) ethyl)-3(p-tolylimino) indolin-2-one

M.P. 217-219 ${ }^{\circ}$; Mol. formula: $\mathrm{C}_{25} \mathrm{H}_{20} \mathrm{~N}_{4} \mathrm{OS}$, yield 74\%. IR $\left(v \mathrm{~cm}^{-1}\right)$ : 3043 (C-H Str, Ar), 2978, 2875 (C-H Str, Aliphatic), 2312 (C-S-C Str), 1729 (C=0 Str, Indole), 1576 (C=N Str), 1521 (C=CH Str), 1465 (C=C Str, Ar). ${ }^{1} \mathrm{H}-\mathrm{NMR}$ (DMSO) $\delta \delta$ ppm: 8.40-8.39 (d, 2H, Ar-H), 8.02-8.00 (d, 2H, Ar-H), 7.877.82 (d, 2H, Ar-H), 7.76 (s, 1H, Ar-H), 7.54-7.50 (d, 2H, Ar-H), 7.34-7.30 $(\mathrm{t}, 2 \mathrm{H}, \mathrm{Ar}-\mathrm{H}), 3.54-3.50\left(\mathrm{~s}, 3 \mathrm{H},-\mathrm{CH}_{3}\right), 3.20-3.10\left(\mathrm{~s}, 3 \mathrm{H},-\mathrm{CH}_{3}\right), 1.90-1.82$ (s, 3H, - $\mathrm{CH}_{3}$ ); Mass (ESI-MS): m/z 424 (M), 425 (M+1, 100\%).

\section{Pharmacological activity: AA[10-12]}

The synthesized compounds are screened for anthelminthic activity using earthworms. Six earthworms of nearly equal size were placed in standard drugsolution and test compound's solutions at room temperature. Normal saline was used as a control. The standard drug and test compounds were dissolved in minimum quantity of DMSO and adjusted the volume up to $10 \mathrm{ml}$ with normal saline solution to get the concentration of $0.1 \% \mathrm{w} / \mathrm{v}$, $0.2 \% \mathrm{w} / \mathrm{v}$, and $0.5 \% \mathrm{w} / \mathrm{v}$. Albendazole was used as a standard drug. The compounds were evaluated by the time taken for complete paralysis and death of earthworms (Figs. 2 and 3). The mean lethal time for each test compound was recorded and compared with standard drug. The time taken by worms to become motionless was noted as paralysis time. The death time of worm was recorded after ascertaining that worms neither moved when shaken nor when given external stimuli. The mean lethal time and paralysis time of the earthworms for different test compounds and standard drug are tabulated in Table 1.

\section{RESULTS AND DISCUSSION}

The synthetic routes are outlined in Schemes 1. In the first case, aniline was heated with ammonium thiocyanate, to obtain 2-amnino

Table 1: Antihelmintic activity of BDIM

\begin{tabular}{|c|c|c|c|c|c|c|c|}
\hline \multirow[t]{3}{*}{ S. No } & \multirow{3}{*}{$\begin{array}{l}\text { Name } \\
\text { Concentration }\end{array}$} & \multicolumn{6}{|c|}{ Time (min) (mean \pm SEM) } \\
\hline & & \multicolumn{3}{|c|}{ For paralysis $\%$ concentration } & \multicolumn{3}{|c|}{ For death \% concentration } \\
\hline & & 0.1 & 0.2 & 0.5 & 0.1 & 0.2 & 0.5 \\
\hline & Control & - & - & - & - & - & - \\
\hline & $\mathrm{AB}$ & $15 \pm 0.121$ & $12 \pm 0.053$ & $8 \pm 0.043$ & $44 \pm 0.043$ & $34 \pm 0.119$ & $26 \pm 0.125$ \\
\hline 1 & $5 a$ & $19 \pm 0.023$ & $15 \pm 0.092$ & $18 \pm 0.120$ & $50 \pm 0.163$ & $47 \pm 0.102$ & $34 \pm 0.127$ \\
\hline 2 & $5 b$ & $31 \pm 0.129$ & $23 \pm 0.120$ & $19 \pm 0.124$ & $52 \pm 0.120$ & $45 \pm 0.134$ & $33 \pm 0.178$ \\
\hline 3 & $5 c$ & $26 \pm 0.031$ & $24 \pm 0.135$ & $20 \pm 0.132$ & $53 \pm 0.172$ & $46 \pm 0.118$ & $35 \pm 0.325$ \\
\hline 4 & $5 \mathrm{~d}$ & $23 \pm 0.051$ & $21 \pm 0.171$ & $18 \pm 0.141$ & $50 \pm 0.153$ & $47 \pm 0.121$ & $38 \pm 0.120$ \\
\hline 5 & $5 e$ & $22 \pm 0.021$ & $19 \pm 0.093$ & $18 \pm 0.021$ & $53 \pm 0.120$ & $42 \pm 0.120$ & $32 \pm 0.321$ \\
\hline 6 & $5 f$ & $23 \pm 0.134$ & $16 \pm 0.122$ & $15 \pm 0.031^{*}$ & $52 \pm 0.052$ & $37 \pm 0.132$ & $31 \pm 0.081$ \\
\hline 7 & $5 g$ & $21 \pm 0.028$ & $24 \pm 0.120$ & $20 \pm 0.154$ & $52 \pm 0.051$ & $46 \pm 0.065$ & $59 \pm 0.031$ \\
\hline 8 & $5 \mathrm{~h}$ & $18 \pm 0.132$ & $18 \pm 0.053$ & $16 \pm 0.120$ & $54 \pm 0.053$ & $42 \pm 0.098$ & $30 \pm 0.101$ \\
\hline 9 & $5 \mathrm{i}$ & $25 \pm 0.032$ & $19 \pm 0.024$ & $19 \pm 0.032$ & $52 \pm 0.121$ & $47 \pm 0.120$ & $35 \pm 0.162$ \\
\hline 10 & $5 j$ & $24 \pm 0.053$ & $20 \pm 0.120$ & $17 \pm 0.120$ & $53 \pm 0.122$ & $45 \pm 0.125$ & $37 \pm 0.154$ \\
\hline 11 & $5 \mathrm{k}$ & $28 \pm 0.125$ & $21 \pm 0.065$ & $14 \pm 0.054$ & $50 \pm 0.187$ & $46 \pm 0.145$ & $39 \pm 0.131$ \\
\hline 12 & 51 & $23 \pm 0.043$ & $23 \pm 0.125$ & $15 \pm 0.132$ & $51 \pm 0.061$ & $44 \pm 0.132$ & $34 \pm 0.124$ \\
\hline 13 & $5 \mathrm{~m}$ & $19 \pm 0.063$ & $19 \pm 0.122$ & $15 \pm 0.120$ & $47 \pm 0.163$ & $37 \pm 0.192$ & $32 \pm 0.120$ \\
\hline 14 & $5 n$ & $18 \pm 0.063$ & $15 \pm 0.043^{*}$ & $10 \pm 0.131^{*}$ & $46 \pm 0.120^{*}$ & $37 \pm 0.120$ & $29 \pm 0.234$ \\
\hline 15 & 50 & $17 \pm 0.145$ & $14 \pm 0.043^{*}$ & $11 \pm 0.132$ & $48 \pm 0.121^{*}$ & $38 \pm 0.165$ & $28 \pm 0.097$ \\
\hline
\end{tabular}

All the results were shown in table and expressed as a mean \pm SEM of six worms in each group, BDIM: Benzothiazole derivatives containing indole moieties,

SEM: Standard error of mean, AB: Albendazole

Table 2: Physical data of compounds 4a-4i

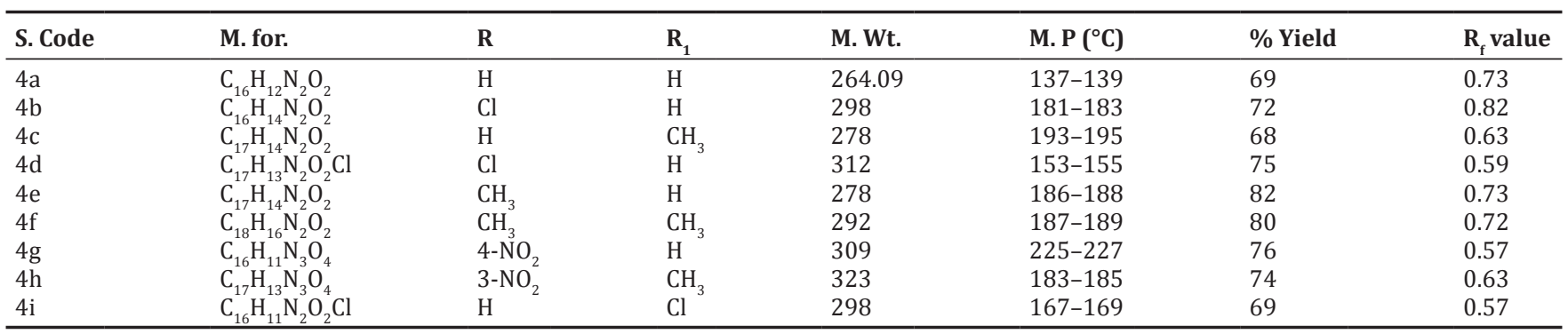

S. Code: Sample code, M. for.: Molecular formula, M. wt.: Molecular weight, M. P: Melting point 
Table 3: Physical data of compounds 5a-5o

\begin{tabular}{|c|c|c|c|c|c|c|c|c|c|}
\hline S. Code & M. for. & $\mathbf{R}$ & $\mathrm{R}_{1}$ & $\mathbf{R}_{2}$ & $\mathbf{R}_{3}$ & M. Wt. & M. P & $\%$ Yield & $\mathbf{R}_{\mathrm{f}} \mathbf{V}$ \\
\hline $5 a$ & $\mathrm{C}_{23} \mathrm{H}_{16} \mathrm{~N}_{4} \mathrm{OS}$ & $\mathrm{H}$ & $\mathrm{H}$ & $\mathrm{H}$ & $\mathrm{H}$ & 396 & 219-221 & 78 & 0.63 \\
\hline $5 b$ & $\mathrm{C}_{23}^{23} \mathrm{H}_{15}{ }_{15} \mathrm{~N}_{4}^{4} \mathrm{OSCl}$ & $\mathrm{H}$ & $\mathrm{H}$ & $\mathrm{Cl}$ & $\mathrm{H}$ & 430 & $213-215$ & 82 & 0.76 \\
\hline $5 c$ & $\mathrm{C}_{24} \mathrm{H}_{18} \mathrm{~N}_{4} \mathrm{OS}$ & $\mathrm{H}$ & $\mathrm{H}$ & $\mathrm{H}$ & $\mathrm{CH}_{3}$ & 410 & 203-205 & 77 & 0.57 \\
\hline $5 \mathrm{~d}$ & $\mathrm{C}_{24}^{24} \mathrm{H}_{17}^{18} \mathrm{~N}_{4}^{4} \mathrm{OSCl}$ & $\mathrm{H}$ & $\mathrm{H}$ & $\mathrm{Cl}$ & $\mathrm{CH}_{3}^{3}$ & 444 & $231-233$ & 66 & 0.61 \\
\hline $5 e$ & $\mathrm{C}_{24}^{24} \mathrm{H}_{18} \mathrm{~N}_{4} \mathrm{OS}$ & $\mathrm{H}$ & $\mathrm{H}$ & $\mathrm{CH}_{3}$ & $\mathrm{H}^{3}$ & 410 & $191-193$ & 67 & 0.53 \\
\hline $5 \mathrm{f}$ & $\mathrm{C}_{25}^{24} \mathrm{H}_{20} \mathrm{~N}_{4} \mathrm{OS}$ & $\mathrm{H}$ & $\mathrm{H}$ & $\mathrm{CH}_{3}^{3}$ & $\mathrm{CH}_{3}$ & 424 & $217-219$ & 74 & 0.81 \\
\hline $5 \mathrm{~g}$ & $\mathrm{C}_{23}^{25} \mathrm{H}_{15}^{20} \mathrm{~N}_{5}^{4} \mathrm{O}_{3} \mathrm{~S}$ & $\mathrm{H}$ & $\mathrm{H}$ & $\mathrm{H}^{3}$ & $\mathrm{NO}_{2}^{3}$ & 441 & $251-253$ & 76 & 0.67 \\
\hline $5 \mathrm{~h}$ & $\mathrm{C}_{24} \mathrm{H}_{17} \mathrm{~N}_{5} \mathrm{O}_{3} \mathrm{~S}$ & $\mathrm{H}$ & $\mathrm{H}$ & $\mathrm{NO}_{2}$ & $\mathrm{CH}_{3}^{2}$ & 455 & $231-233$ & 81 & 0.51 \\
\hline $5 \mathrm{i}$ & $\mathrm{C}_{23}^{24} \mathrm{H}_{15}^{11} \mathrm{~N}_{4}^{3} \mathrm{OSCl}$ & $\mathrm{H}$ & $\mathrm{H}$ & $\mathrm{H}^{2}$ & $\mathrm{Cl}^{3}$ & 430 & $187-189$ & 78 & 0.83 \\
\hline $5 j$ & $\mathrm{C}_{23} \mathrm{H}_{14} \mathrm{~N}_{4} \mathrm{OSClF}$ & $\mathrm{Cl}$ & $\mathrm{F}$ & $\mathrm{H}$ & $\mathrm{H}$ & 448 & $231-233$ & 80 & 0.59 \\
\hline $5 \mathrm{k}$ & $\mathrm{C}_{24}^{23} \mathrm{H}_{16} \mathrm{~N}_{4} \mathrm{OSClF}$ & $\mathrm{Cl}$ & $\mathrm{F}$ & $\mathrm{CH}_{3}$ & $\mathrm{H}$ & 462 & 193-195 & 78 & 0.75 \\
\hline 51 & $\mathrm{C}_{25}^{24} \mathrm{H}_{18} \mathrm{~N}_{4} \mathrm{OS}$ & $\mathrm{Cl}$ & $\mathrm{F}$ & $\mathrm{CH}_{3}^{3}$ & $\mathrm{CH}_{3}$ & 476 & $215-217$ & 78 & 0.84 \\
\hline $5 \mathrm{~m}$ & $\mathrm{C}_{23}^{23} \mathrm{H}_{13} \mathrm{~N}_{4}^{4} \mathrm{OSFCl} \mathrm{SL}_{2}$ & $\mathrm{Cl}$ & $\mathrm{F}$ & $\mathrm{H}^{3}$ & $\mathrm{Cl}$ & 482 & $263-265$ & 81 & 0.66 \\
\hline $5 \mathrm{n}$ & $\mathrm{C}_{23}^{23} \mathrm{H}_{13}^{13} \mathrm{~N}_{5}^{4} \mathrm{SClF}$ & $\mathrm{Cl}$ & $\mathrm{F}$ & $\mathrm{NO}_{2}$ & $\mathrm{H}$ & 493 & $243-245$ & 68 & 0.71 \\
\hline 50 & $\mathrm{C}_{23}^{23} \mathrm{H}_{13} \mathrm{~N}_{4}^{3} \mathrm{OSCl}_{2} \mathrm{~F}$ & $\mathrm{Cl}$ & $\mathrm{F}$ & $\mathrm{Cl}^{2}$ & $\mathrm{H}$ & 482 & $225-227$ & 76 & 0.77 \\
\hline
\end{tabular}

S. Code: Sample code, M. for: Molecular formula, M. wt.: Molecular weight, M. P: Melting point, $\mathrm{R}_{\mathrm{f}} \mathrm{V}: \mathrm{R}_{\mathrm{f}}$ value

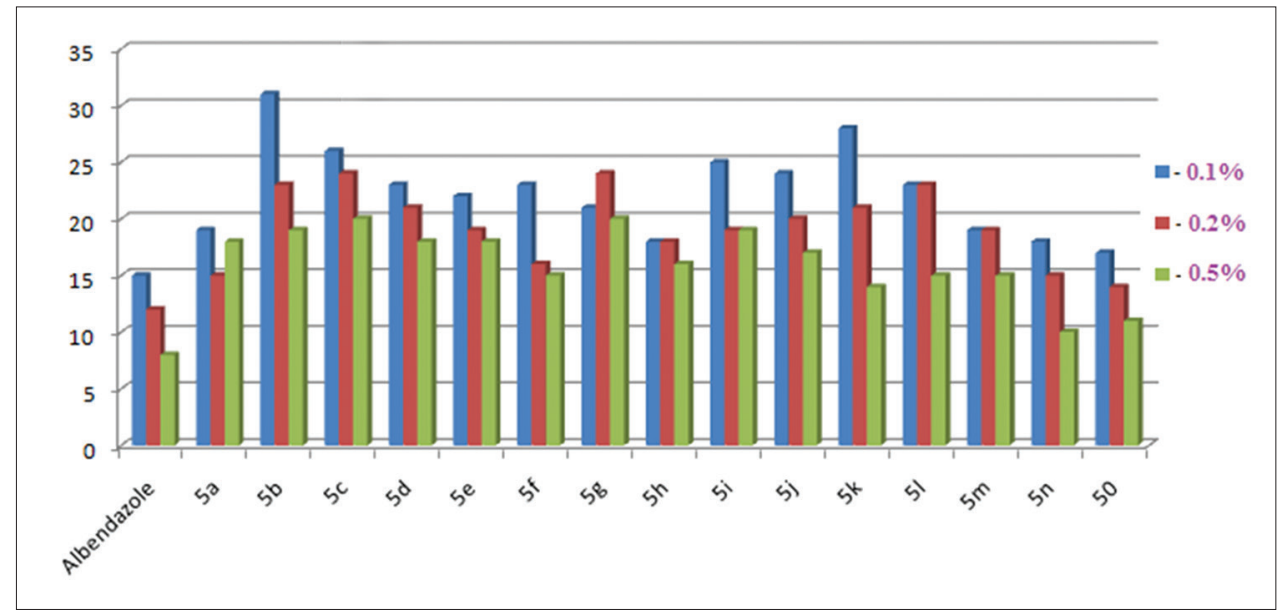

Fig. 2: Graphical representation of anthelmintic activity of compounds (5a-50) - Paralysis time (min)

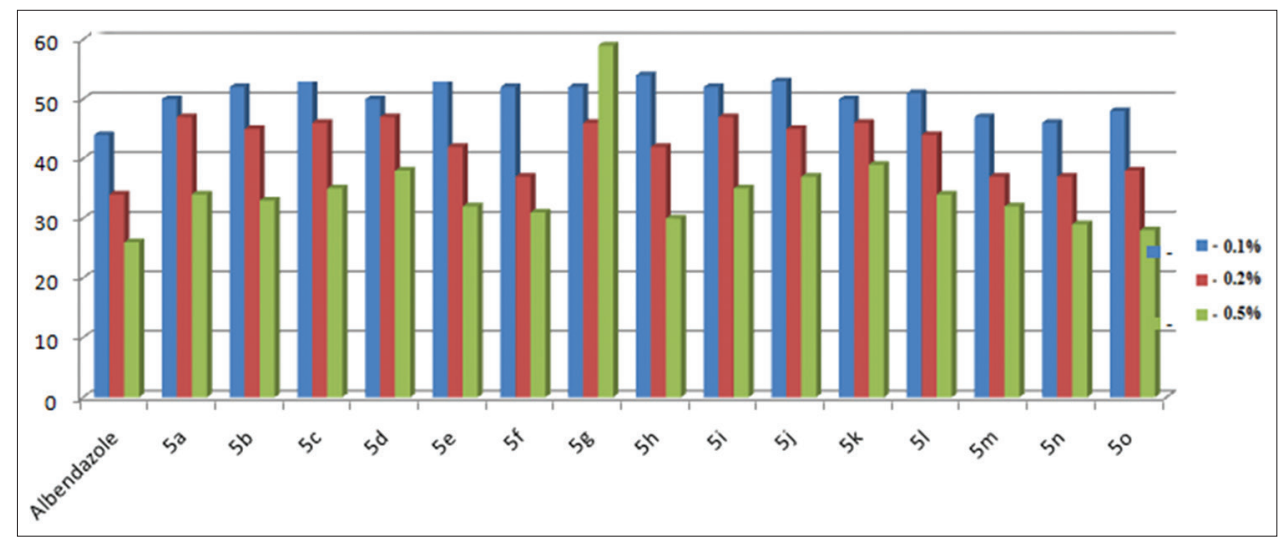

Fig. 3: Graphical representation of anthelmintic activity of compounds (5a-5o) - Death time (min)

benzothiazole (2-ABT). The substituted ISBs undergo acetylation and react with 2-ABT to give novel BDIM. The physical data results are shown in Tables 2 and 3. The synthesized compounds were screened for AA. The structures of all the newly synthesized compounds were characterized as $5 \mathrm{a}-5 \mathrm{o}$ on the basis of satisfactory analytical and spectral data including IR, LC-Mass, and ${ }^{1}$ H NMR data.

\section{AA}

The synthesized compounds (5a-5o) were evaluated for AA on Indian earthworms (Pheretima posthuma). All compounds showed that
AA is shown in Table 1. A closer inspiration of data from this table indicated that the synthesized compounds $\mathbf{5 f}, \mathbf{5 n}$, and $\mathbf{5 o}$ showed good AA, whereas others showed significant activities. After all, the synthesized compounds in overall estimation confirm the better activity against $P$. posthuma. The results are shown in Figs. 2 and 3.

The statistical analyses were carried out using one-way analysis of variance (Dunnett's test) at a 95\% confidence interval, and all the activity data on comparison with vehicle control reach statistical significance with $\mathrm{p}<0.05$ (Fig. 4). 


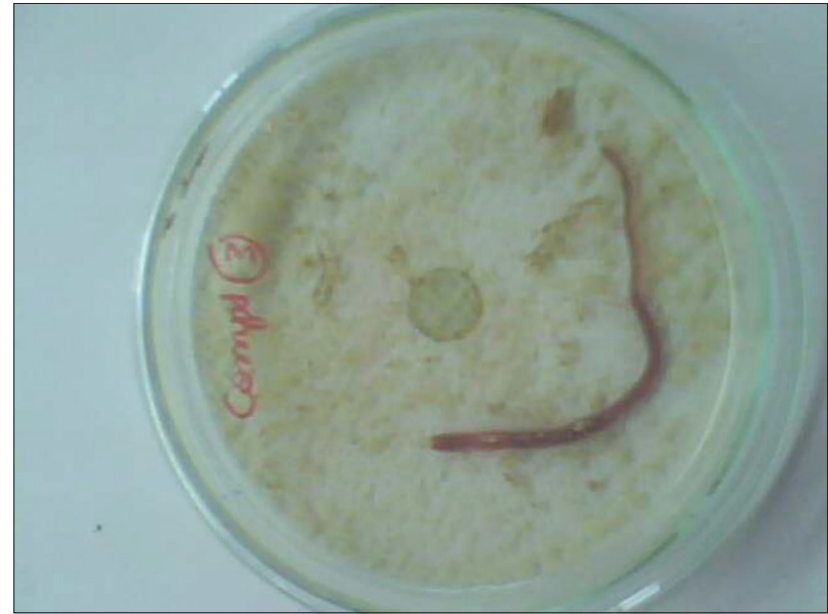

Fig.4: Photographs of various benzothiazole derivatives - Anthelmintic activities

\section{CONCLUSION}

The present study highlights the importance of benzothiazole derivatives having various heterocyclic moiety features responsible for the AA and may serve as a lead molecule for further modification to obtain clinically useful novel entities. The AA of all the synthesized compounds showed moderate activity.

\section{AUTHORS' CONTRIBUTIONS}

The corresponding author has done all the work, interpreted the data, and written the manuscript.

\section{CONFLICTS OF INTEREST}

The authors declare that they have no conflicts of interest. The authors alone are responsible for the content and writing of the paper.

\section{REFERENCES}

1. Catalano A, Desaphy JF, Lentini G, Carocci A, Di Mola A, Bruno C, et al. Synthesis and toxicopharmacological evaluation of m-hydroxymexiletine, the first metabolite of mexiletine more potent than the parent compound on voltage-gated sodium channels. J Med Chem 2012;55:1418-22

2. Carocci A, Catalano A, Lovece A, Lentini G, Duranti A, Lucini V, et al. Design, synthesis, and pharmacological effects of structurally simple ligands for MT1 and MT2 melatonin receptors. Bioorg Med Chem 2010;18:6496-511.

3. Baell JB, Duggan PJ, Forsyth SA, Lewis RJ, Lok YP, Schroeder CI, et al. Synthesis and biological evaluation of nonpeptide mimetics of omega-conotoxin GVIA. Bioorg Med Chem 2004;12:4025-37.

4. Gaware VM, Dhamak KB, Kotade KB. Synthesis and evalution of benzothiazole derivatives for anthelmintic activity. Eur J Pharm Med Res 2016;3:454-9.

5. Cavalluzzi MM, Bruno C, Lentini G, Lovece A, Catalano A, Carocci A, et al. One-step synthesis of homochiral O-aryl and O-heteroaryl mandelic acids and their use as efficient $1 \mathrm{H}$ NMR chiral solvating agents. Tetrahedron Asymmetry 2009;20;1984-91.

6. Siddiqui N, Rana A, Khan SA, Bhat MA, Haque SE. Synthesis of benzothiazole semicarbazones as novel anticonvulsants the role of hydrophobic domain. Bioorg Med Chem Lett 2007;17:4178-82.

7. Kaur H, Kumar S, Singh I, Saxena KK, Kumar A. Synthesis, characterization and biological activity of various substituted benzothiazole derivatives. Dig J Nanomater Biostruct 2010;5:67-76.

8. Leena KP, Subin MZ, Deepthy CH. In silico design, synthesis and characterization of some novel benzothiazole derivatives as anticancer agents. Asian J Pharm Clin Res 2017;10:50-15.

9. Mohammed JM. Synthesis, characterization and preliminary antimicrobial evaluation of new Schiff bases of ampicillin and amoxicillin derived from isatin derivatives. Int J Pharm Pharm Sci 2016;8:113-6.

10. Ajaiyeoba EO, Onocha PA, Olarenwaju OT. In vitro anthelmintic properties of Buchholzia coriaceae and Gynandropsis gynandra extract. Pharm Biol 2001;39:217-20.

11. Maneshwar T, Krishna M, Vijetha N. Synthesis, characterization and biological evaluation of novel benzimidazole derivatives. J Pharm Res 2015;4:188-92.

12. Himaja M, Sirisha B, Moonjit D, Munirasekhar D. Synthesis and anthelmintic activity studies of 1-substituted benzimidazole derivatives. J Indian Chem Soc 2015;92:908-10. 